Produto \& Produção, vol. 18, n. 1, p. 53-61, 2017.

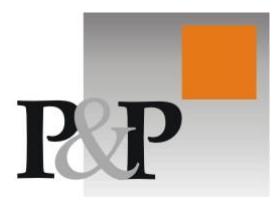

RECEBIDO EM 31/03/2017. ACEITO EM 26/04/2017.

\author{
Cláudia de Souza Libânio \\ Universidade Federal de Ciências da Saúde de Porto Alegre - UFCSPA e Unisinos \\ clasl@terra.com.br
}

Fernando Gonçalves Amaral

Universidade Federal do Rio Grande do Sul-UFRGS

amaral@producao.ufrgs.br

Sérgio Almeida Migowski

Instituto Federal do Rio Grande do Sul - IFRS

sergiomigowski@gmail.com

\title{
Estrutura e Fatores Intervenientes na Gestão de Design
}

\section{Resumo}

As empresas brasileiras vêm demonstrando interesse em investir em design, percebendo-o como um elemento estratégico para a obtenção de vantagem competitiva. Sendo assim, este artigo objetiva mapear a estrutura e identificar fatores intervenientes da gestão de design em empresas brasileiras pertencentes à indústria do vestuário. Foi realizada uma pesquisa exploratória, de abordagem qualitativa, com a aplicação de entrevistas em profundidade com quatro especialistas em design de moda. Como resultados, foi desenvolvido um mapa conceitual e elaborada a Árvore da Realidade Atual (ARA), com base no processo de pensamento. Foi possível levantar conceitos relacionados à gestão de design bem como identificar a dificuldade de sua implementação nas organizações brasileiras pertencentes à indústria do vestuário. Ademais, por meio do desenvolvimento da ARA, foram identificadas e elencadas as prováveis causas, ou seja, os eventuais fatores intervenientes capazes de gerar o efeito da não ocorrência da gestão de design nas empresas da referida indústria.

Palavras-chave: Gestão de Design, Mapa Conceitual, Árvore da Realidade Atual

\begin{abstract}
Brazilian companies has shown interest in investing in design, perceiving it as a strategic element for achieving competitive advantage. Thus, this article aims to map the structure and identify intervening factors in design management in Brazilian companies belonging to the garment industry. The methodology was exploratory, qualitative, through in-depth interviews with four experts in fashion design. As a result, a conceptual map was developed and the current reality tree (ARA) was drawn, based on the thought process. It was possible to point out concepts related to design management and to identify the difficulty of its implementation in brazilian organizations belonging to the garment industry. Moreover, by developing the ARA, the probable causes were listed, that is, any intervenient factors capable of generating the effect of non-occurrence of design management in this industry companies.
\end{abstract}

Keywords: Design Management, Conceptual Map, Current Reality Tree 


\section{Introdução}

De maneira geral, as empresas buscam direcionar seus recursos financeiros a produtos, serviços e desenvolvimento de pesquisa no intuito de criar e inovar, diferenciando seus produtos e serviços dos de seus concorrentes. Com isso, as organizações vêm demonstrando interesse em investir em design, percebendo-o como um elemento estratégico para a obtenção de vantagem competitiva. Segundo Borja de Mozota (2003), se tratado como elemento estratégico, o design deve ter relação com a missão e os valores da empresa, bem como com o seu planejamento estratégico. A autora também defende que a cultura e as ações da organização estejam conectadas e em sintonia com o design, objetivando o alcance de melhores resultados pela empresa.

Nesse contexto, um dos setores que tem buscado se desenvolver através do design é a indústria do vestuário, destacando-se tanto internacionalmente quanto nacionalmente. No contexto mundial, o Brasil está entre os quatro principais países produtores de artigos têxteis (ABIT, 2015). Ademais, a região sul do Brasil é a segunda principal região brasileira produtora de roupas, ficando atrás somente da região sudeste (ABRAVEST, 2014). O setor do vestuário do Estado do Rio Grande do Sul representa mais de 7.500 das indústrias brasileiras e emprega ao redor de 21.000 trabalhadores. Entretanto, percebe-se que, na indústria internacional do vestuário, o design é tratado como elemento estratégico, e que o Brasil ainda é tido, por vezes, como um seguidor de tendências internacionais (LIBÂNIO, AMARAL, 2014). Apesar deste fato, nota-se que as organizações brasileiras vêm, gradativamente, demonstrando interesse em investir em design (LIBÂNIO, 2011). Todavia, para que este investimento tenha o retorno esperado, é necessário que o design seja tratado como um elemento estratégico, passando a ser entendido como um processo, e portanto, podendo ser gerenciado.

\subsection{Gestão de Design}

Ao longo das últimas décadas, a gestão de design vem sendo discutida e entendida como uma atividade multidisciplinar, que forma parceiros de trabalho e integra o design no ambiente organizacional (LIBÂNIO, AMARAL, 2011; BORJA DE MOZOTA, 2003; BEST, 2006). No intuito de estabelecer um conceito formal e na tentativa de encontrar um significado que se aplique efetivamente às empresas, definições de Gestão de Design são propostas destacando os níveis das atividades organizacionais, seus agentes participantes, bem como as funções e formas de atuação desses agentes. Borja de Mozota (2003) conceitua gestão de design como a implantação do design por meio de um programa formal de atividades na organização, reconhecendo sua relevância para os objetivos de longo prazo da companhia, coordenando os seus recursos em todos os níveis da atividade corporativa, almejando alcançar os objetivos da empresa. Já o Design Management Institute - DMI (2016) afirma que a gestão de design engloba os processos em andamento, as decisões de negócios e as estratégias que permitem a inovação e a criação de produtos, serviços, comunicações, ambientes e marcas com um design efetivo, que melhoram a qualidade de vida das pessoas e proporcionam o sucesso organizacional. Best (2006) complementa o entendimento da gestão de design destacando que esta pode ser compreendida como a gestão de projetos de design e acrescenta que a gestão de design desempenha um papel de liderança estratégica, demonstrando como o design pode contribuir positivamente para a organização de diferentes maneiras.

Desta maneira, percebe-se que o design vai além da concretização da forma unicamente. Gerenciar o design envolve uma atividade multidisciplinar (BORJA DE MOZOTA, 2003), agindo diretamente na estrutura e nas relações funcionais das empresas e integrando as diversas equipes de trabalho envolvidas em determinado projeto. Ademais, na gestão de design, incentiva-se que profissionais de design possam participar ao longo de todo o processo de definições de diretrizes, planejamento, produção e lançamento do produto no mercado, estimulando uma atividade multidisciplinar entre as equipes de trabalho envolvidas em determinado projeto. Magalhães (1994) afirma que, para utilizar o design de maneira estratégica, ele deve estar integrado e fazer parte da estratégia da empresa, a partir do nível decisório mais alto, interagindo com todas as áreas relevantes envolvidas no projeto.

Por ter um caráter multidisciplinar, a gestão de design trata de diversos recursos (internos e externos) e integra indivíduos com competências específicas. Borja de Mozota (2003) salienta que "é estratégico construir a vantagem competitiva por meio de recursos internos". Ademais, de acordo com 
Davenport e Prusak (1998), recursos podem representar vantagem competitiva para as organizações. Crawford (2005) afirma que as competências não são um único constructo isolado. Belkadi, Bonjour, e Dulmet (2007) reforçam que as competências são ativadas baseadas nas características de situações de trabalho e que a construção destas competências podem ocorrer por meio da revisão de projetos anteriormente desenvolvidos. Como características das competências referidas, podem ser destacadas a combinação de recursos internos e externos e a aplicação de competências em design para gerenciar recursos e guiar as decisões estratégicas de negócios (BERTOLA; TEIXEIRA, 2003). Alguns estudos (BELKADI, BONJOUR, E DULMET; 2007, BOUCHER, BONJOUR, E GRABOT; 2007, OSTERLUND E LOVEN; 2005) enfatizam que a classificação destas competências ocorrem em nível individual, coletivo e organizacional. Diante da relevância da gestão de design para as empresas inseridas na indústria do vestuário bem como de seu caráter multidisciplinar, este artigo objetiva mapear a estrutura e identificar fatores intervenientes da gestão de design em empresas brasileiras da referida indústria.

\section{Método}

O método utilizado neste trabalho foi exploratório, seguindo uma abordagem qualitativa e sendo conduzido por meio de pesquisa bibliográfica bem como de entrevistas em profundidade (MALHOTRA, 2012). De acordo com Flick (2008), a pesquisa qualitativa foca na perspectiva dos entrevistados, em suas práticas diárias, e em seu conhecimento rotineiro sobre a questão a ser estudada. A amostra é não probabilística, escolhida por conveniência. De acordo com Malhotra (2012), para este tipo de pesquisa, a amostra é pequena e não-representativa, gerando o máximo de discernimento e podendo fazer uso, por exemplo, de entrevistas pessoais com especialistas de determinado setor. Foram entrevistados quatro especialistas em design de moda. O especialista 1 (E1) é designer, com título de doutor em design e experiência de 15 anos no mercado da moda. Já o especialista 2 (E2) tem graduação em desenho industrial, doutorado em engenharia de produção e experiência de 15 anos no mercado do vestuário. Os especialistas 3 (E3) e 4 (E4) são designers, mestres em design e estão com doutorado em andamento. O E3 possui 23 anos de experiência no mercado da moda e o E4 possui 14 anos de experiência no mercado da moda. Os E1, E3 e E4 atuam nacionalmente e o E2 atua nacionalmente e internacionalmente no mercado da moda.

A técnica utilizada foi a entrevista do tipo não-estruturada, na modalidade de entrevista focalizada (MARCONI; LAKATOS, 2003). Foi elaborado um roteiro de perguntas e tópicos para utilização nas entrevistas em profundidade. Segundo Malhotra (2012), os especialistas são pessoas bem informadas a respeito do assunto e do setor de atuação. As entrevistas foram gravadas, transcritas e os dados tabulados para posterior análise. A partir dos dados coletados, foi realizada uma análise de conteúdo (BARDIN, 2005), almejando atingir os objetivos desta pesquisa.

Analisados os dados obtidos por meio das entrevistas individuais com os quatro especialistas em design de moda, foi desenvolvido um mapa conceitual do tipo hierárquico, objetivando identificar conceitos referentes aos indivíduos, equipes e organização, bem como suas competências, ressaltando possíveis relacionamentos entre esses conceitos. Novak e Cañas (2008) definem mapas conceituais como ferramentas gráficas para organizar e representar o conhecimento. Os autores salientam que os mapas conceituais devem partir de conceitos mais gerais nos níveis mais altos para conceitos mais específicos nos níveis mais abaixo, apresentando uma estruturação hierárquica dos conceitos elencados, e fazendo uso tanto por meio de diferenciação progressiva quanto de uma reconciliação integrativa. Em outro estudo, Novak e Cañas (2006) conceituam a diferenciação progressiva como um desdobramento de conceitos, e a reconciliação integrativa como o relacionamento de um conceito com outro que, aparentemente, não teria relação.

Por meio da análise dos dados do mapa conceitual, foi possível perceber a dificuldade de ocorrência e/ou implementação da gestão de design nas organizações. Desta maneira, optou-se por desenvolver a árvore da realidade atual (ARA), visando identificar os problemas centrais relacionados à dificuldade de ocorrência da gestão de design. Foram feitas três reuniões para construção da ARA com a participação de outros três especialistas que não participaram da etapa das entrevistas para a elaboração do mapa conceitual. Dois especialistas tem titulação de mestre e um é $\mathrm{PhD}$. Os três especialistas trabalham com engenharia de produção e tem foco de pesquisa em gestão de projetos e gestão de design. Entre os métodos utilizados pela Teoria das Restrições (TOC) pode ser citado o 
processo de pensamento, que utiliza a ARA como uma das ferramentas para identificar um problema por meio de sua causa e efeito. Segundo Blackstone (2001), a ARA é utilizada para identificar problemas centrais em um determinado sistema, buscando respostas sobre o que é passível de mudança por meio de relações de causa e efeito.

\section{Resultados e Discussão}

A partir do objetivo proposto pelo artigo e dos dados coletados com os especialistas, foram elaborados um mapa conceitual e a árvore da realidade atual, no sentido de contribuir para uma discussão sobre o tema.

Ao longo das entrevistas, todos os especialistas afirmaram que, para a ocorrência da gestão de design nas empresas, estas devem ter a percepção do design como um valor, inserido nas estratégias organizacionais e utilizado como elemento estratégico para o alcance da vantagem competitiva sustentável. O E1 ressalta que "o design deve afetar todos os níveis de uma organização, indo além do seu departamento". O E2 acrescenta que "deve ser estabelecido nas empresas um percurso de empoderamento do design em termos de gestão do negócio". Este pensamento vai ao encontro do entendimento de Borja de Mozota (2003), que destaca que o design deve ter relação com os valores da empresa e com o seu planejamento estratégico. A autora salienta ainda que, desta forma, a cultura e as ações da organização estarão conectadas com o design. Essas organizações são chamadas de empresas orientadas para o design e são norteadas por estratégias de design.

As competências individuais relatadas pelos especialistas para o profissional de design estão relacionadas ao âmbito do projeto, por meio de conhecimentos técnicos, conhecimentos específicos, multidisciplinares, de mercado e do negócio da empresa. As habilidades estão mais focadas em projeto e prototipagem, no acompanhamento de mercado, na alteridade, na comunicação e no planejamento da coleção. Já a postura atitudinal trata da busca pelo entrosamento nos sistemas design e moda, do engajamento com os seus pares, com a organização, sua filosofia e negócio. Os especialistas ainda ressaltaram a importância do desenvolvimento e incentivo no aprendizado da linguagem de negócios aos designers e de design aos gestores (E1 e E3) bem como da dificuldade de comunicação entre setores das empresas (E2). O especialista E2 salientou a dificuldade de comunicação em função das diferentes culturas e idiomas, na importação e exportação de produtos e matérias primas.

Com relação ao entendimento do conhecimento como um recurso, os especialistas ressaltaram que a criação, transmissão e retenção de conhecimentos ocorrem em determinados momentos na etapa de desenvolvimento de uma coleção, como na pesquisa de tendências e criação da coleção, no acompanhamento da produção da peça piloto e na apresentação da coleção, tanto para validação para produção quanto para os representantes comerciais e envolvidos no ponto de venda. Os especialistas também afirmaram a importância da transformação do conhecimento tácito em explícito.

Os especialistas E1 e E4 destacaram que algumas ações devem ser incorporadas como rotinas nas organizações. Deram o exemplo da retenção e armazenamento de informações. Segundo estes especialistas, esta retenção de dados e informações pode ocorrer por meio de: backups de coleções passadas; relatórios estatísticos de vendas, performance dos produtos no mercado; e pesquisas de satisfação de clientes, de consumo e de demandas de mercado. Todos os especialistas ressaltaram ser primordial os momentos de aprendizado, bem como a constante comunicação entre os indivíduos da equipe de design e entre as equipes, para ocorrência da gestão de design.

Para auxiliar na proposição de possíveis relações entre os pontos discutidos, foi desenvolvido um mapa conceitual hierárquico, partindo da relação da gestão de design com três eixos determinantes: indivíduos, equipes e organização, conforme ilustra a figura 1. Por meio desse mapa conceitual, foi possível levantar conceitos relacionados à gestão de design, tais como: indivíduos e equipes envolvidos na gestão de design bem como a própria organização; competências individuais, coletivas e organizacionais; atividades multidisciplinares; rotinas; capacidades dinâmicas; fatores intervenientes; relações; articulações e vantagem competitiva sustentável. Com base nesses conceitos, foram sugeridos alguns agrupamentos, possíveis relações e até mesmo níveis de dependência. 


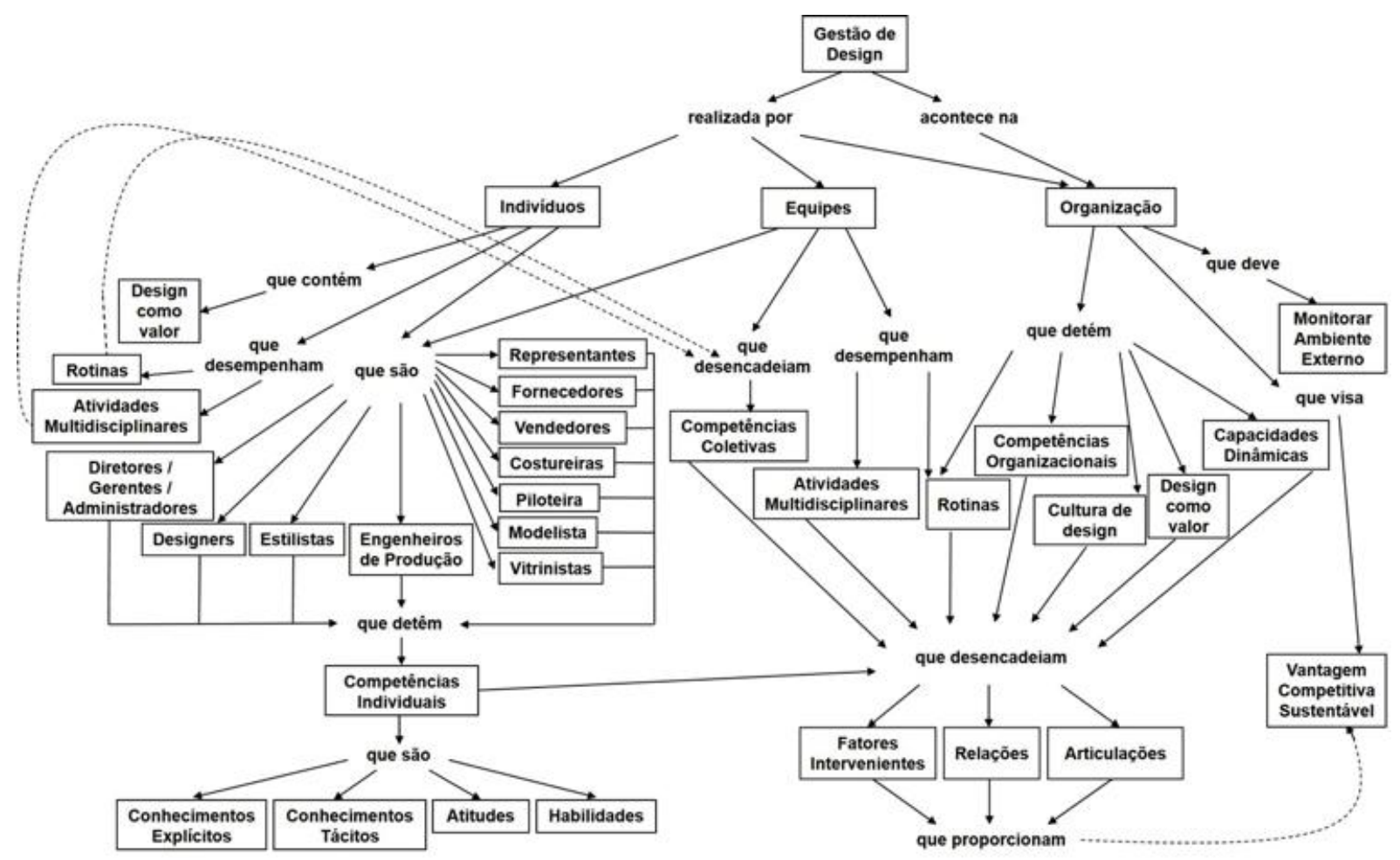

Figura 1 - Mapa Conceitual destacando os conceitos relacionados à gestão de design e possíveis articulações

Os conceitos mais amplos, como indivíduos, equipes e organização, são desdobrados em conceitos mais específicos, evidenciando a chamada diferenciação progressiva, conforme proposto por Novak e Cañas (2006). Já a reconciliação integrativa pode ser observada na figura 1 através de linhas tracejadas, sugerindo um relacionamento entre rotinas e atividades multidisciplinares dos indivíduos que desencadeiam competências coletivas; ou pelos fatores intervenientes, relações e articulações que, em conjunto, vão proporcionar a vantagem competitiva sustentável às organizações. Uma interpretação feita a partir da leitura deste mapa conceitual é que a gestão de design necessita de uma organização que tenha uma cultura de design, que, tanto a organização quanto os seus integrantes, tenham o entendimento do design como um valor estratégico para a empresa, que desempenhe atividades multidisciplinares, capacidades dinâmicas, rotinas e competências organizacionais e que busque uma vantagem competitiva sustentável; que tenha equipes e pessoas com determinadas competências, desempenhem funções e atividades de maneira multidisciplinar e que, ao trabalhar em equipe e executar rotinas, gerem competências coletivas.

Por meio da análise dos dados das entrevistas com os especialistas em design de moda, também foi possível perceber a dificuldade de ocorrência e/ou implementação da gestão de design nas organizações pertencentes à indústria do vestuário. Desta maneira, foi elaborada a Árvore da Realidade Atual (ARA) nos moldes propostos por Blackstone (2001) e Cox e Spencer (2002), conforme ilustra a figura 2. Através dessa ferramenta, foi possível identificar e elencar as prováveis causas, ou seja, os prováveis fatores intervenientes que geram o efeito da não ocorrência da gestão de design.

A árvore da realidade atual possibilita a melhor visualização das prováveis causas que geram o efeito em questão. Através da figura 2, percebe-se que determinadas causas estão relacionadas à falta de ações e/ou materiais de apoio. Já outras causas estão relacionadas ao 'como fazer' ou então concernem às competências, qualificações e capacitações dos agentes que atuam direta ou indiretamente na gestão de design.

A primeira causa raiz diz respeito à dificuldade no entendimento do design como valor. Quando tratado como elemento estratégico nas organizações, o design tem relação com a missão, os valores e o planejamento estratégico da empresa, de acordo com Borja de Mozota (2003). A autora também defende que a cultura e as ações da organização estão conectadas e em sintonia com o design, tendo 
como objetivo o alcance de melhores resultados pela empresa. Essas organizações são chamadas de empresas orientadas para o design. Seguindo este ponto de vista, Capaldo (2007) aborda o design como valor e como processo de criação de valor. Ravasi e Lojacono (2005) enfatizam o entendimento do design como um recurso central da organização e Olson, Cooper e Slater (1998) complementam que o design deve refletir os valores corporativos, relacionando as estratégias empresariais e evidenciando a importância deste fazer parte dos objetivos estratégicos das empresas. Para promover uma atividade multidisciplinar, indivíduos, equipes e interlocutores em uma companhia devem compartilhar informações constantemente, trabalhando de maneira integrada (BORJA DE MOZOTA, 2003; BEST, 2006) e incentivando um ambiente de trabalho colaborativo e participativo.

Já a segunda causa raiz identificada na ARA concerne à dificuldade na articulação de competências coletivas e individuais. Belkadi, Bonjour e Dulmet (2007) salientam que as competências são articuladas a partir de características qualitativas das situações de trabalho e a construção destas pode ocorrer a partir da revisão de projetos passados. Os autores enfatizam as conexões das competências com o conhecimento e a situação. Os autores acrescentam que o design pode ser interpretado como uma atividade que pode gerar novos conhecimentos e integrar conhecimentos heterogêneos. Desta maneira, as competências individuais podem ser construídas, segundo Loufrani-Fedida e Angué (2009), levando em conta os conhecimentos (saber) e as experiências práticas (saber-fazer e/ou saber-agir), sendo alicerçados pelo comportamento (saber-ser). Já as competências coletivas, segundo Retour (2012), por seu caráter tácito e pela sua complexidade, são específicas das firmas e, por isso, dificilmente imitáveis. Podem ser desenvolvidas e articuladas à partir de rotinas de trabalho e processos de trabalho específicos de cada empresa. 


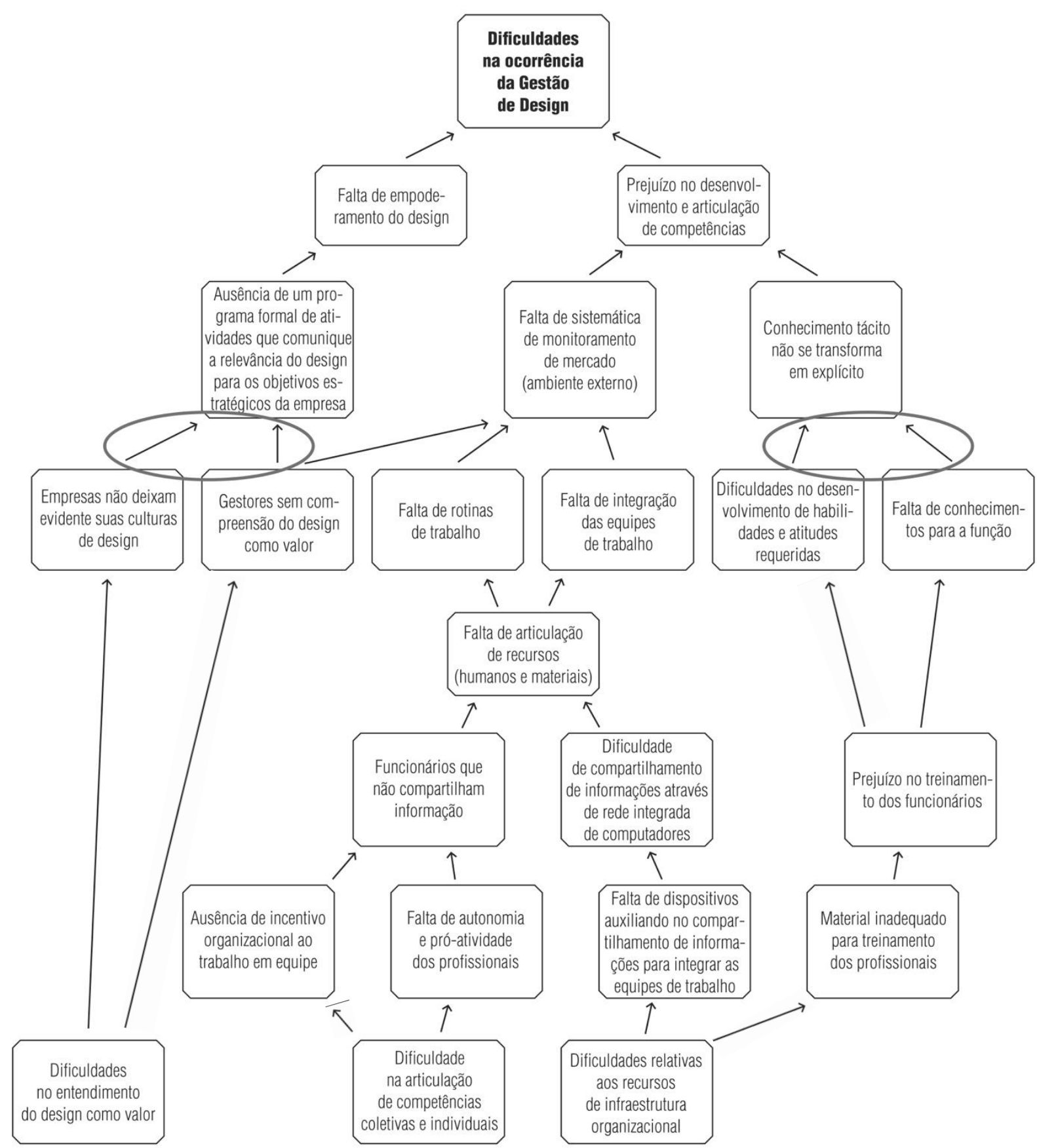

Figura 2 - Árvore da Realidade Atual dos os prováveis fatores intervenientes que geram o efeito da não ocorrência da gestão de design

A terceira causa raiz está ligada às dificuldades relativas aos recursos de infraestrutura organizacional. A partir da combinação de recursos internos e externos (BERTOLA; TEIXEIRA, 2003; BRUCE; COOPER; VAZQUEZ, 1999) bem como da sua integração, coordenação, colaboração e comunicação (MISHRA; SHAN, 2009), estes recursos, quando relacionados aos indivíduos e a infraestrutura de trabalho, podem ser articulados para o alcance da vantagem competitiva sustentável e para a ocorrência da gestão de design. Uma estrutura com boas informações e uma cultura existente de valores e termos comuns (OSTERLUND; LOVEN, 2005) também colaboram para esta ocorrência.

Ressalta-se duas ocorrências em que uma causa não foi suficiente para gerar um efeito. Na primeira, lê-se: se as empresas não deixam evidente sua cultura de design e se há gestores sem compreensão do design como valor, então há a ausência de um programa formal de atividades que comunique a relevância do design para os objetivos estratégicos da empresa. Na segunda, lê-se: se há 
dificuldades no desenvolvimento de habilidades e atitudes requeridas e se há falta de conhecimentos para a função, então o conhecimento tácito não se transforma em explícito.

\section{Conclusões}

A partir deste estudo, foi possível identificar conceitos referentes aos indivíduos, equipes e organização na estrutura da gestão de design, bem como fatores intervenientes na ocorrência deste processo. Por meio da elaboração do mapa conceitual, foram apontados conceitos referentes aos indivíduos, equipes e organização, bem como suas competências, ressaltando possíveis relacionamentos entre esses conceitos. A partir do desdobramento mais amplo, evidenciaram-se conceitos mais específicos, tais como: indivíduos e equipes envolvidos na gestão de design bem como a própria organização; competências individuais, coletivas e organizacionais; atividades multidisciplinares; rotinas; capacidades dinâmicas; fatores intervenientes; relações; articulações e vantagem competitiva sustentável.

Também foi desenvolvida a árvore da realidade atual (ARA), a partir da percepção da dificuldade de ocorrência da gestão de design nas organizações pertencentes à indústria do vestuário. A escolha pelo estudo da indústria brasileira do vestuário deveu-se às suas características particulares como: a alta representatividade no contexto econômico e social do país, a proximidade com o consumidor final, o elevado número de agentes envolvidos em seus sistemas produtivos e o acentuado dinamismo do mercado.

A partir da elaboração da ARA, foi possível perceber os problemas centrais relacionados à dificuldade de ocorrência da gestão de design. A primeira causa raiz diz respeito à dificuldade no entendimento do design como valor. Já a segunda causa raiz identificada na ARA concerne à dificuldade na articulação de competências coletivas e individuais. A terceira causa raiz está ligada às dificuldades relativas aos recursos de infraestrutura organizacional. Identificou-se que determinadas causas estão relacionadas à falta de ações e/ou recursos de infraestrutura organizacional. Já outras causas estão relacionadas ao 'como fazer' ou então concernem às competências, qualificações e capacitações dos agentes que atuam direta ou indiretamente na gestão de design.

Nas empresas pertencentes a indústria vestuário, percebe-se a criação e a ocorrência de conhecimento e informação específicos do setor, seja a partir do processo de trabalho individual ou de rotinas e da integração de equipes. Arranjos internos, rotinas e práticas de trabalho poderiam auxiliar no mapeamento destas ocorrências para que, assim, seja possível gerenciar as atividades e recursos envolvidos na gestão de design.

Ademais, conclui-se que a gestão de design necessita de uma organização que tenha uma cultura de design, que tanto a organização quanto os seus integrantes tenham o entendimento do design como um valor estratégico para a empresa, que desempenhe atividades multidisciplinares, capacidades dinâmicas, rotinas e competências organizacionais e que busque uma vantagem competitiva sustentável; que tenha equipes e pessoas com determinadas competências, desempenhem funções e atividades de maneira multidisciplinar e que, ao trabalhar em equipe e executar rotinas, gerem competências coletivas.

\section{Referências}

ABIT - Associação Brasileira de Indústria Têxtil e Confecção. O Poder da Moda: agenda de competitividade da indústria têxtil e de confecção brasileira 2015 a 2018. ABIT, São Paulo, 2015.

ABRAVEST - Associação Brasileira da Indústria do Vestuário. Dados Estatísticos do Setor do Vestuário. Disponível em: <www.abravest.org.br>. Acessado em: 25 de março, 2014.

BARDIN, L. Análise de conteúdo. ed. rev. e atual. Lisboa: Edições 70, 2005.

BELKADI, F.; Bonjour, E.; Dulmet, M. Competency characterization by means of work situation modeling. Computers in Industry, 2007, v. 58, p. 164-178.

BERTOLA, P.; Teixeira, J.C. Design as a knowledge agent: How design as a knowledge process is embedded into organizations to foster innovation. Design Studies, 2003, v. 24, No. 2, p. 181-194. 
BEST, K. Design Management: managing design strategy, process and implementation. Lausanne: AVA, 2006.

BLACKSTONE, J.H. Theory of Constraints: a status report. International Journal Production Research, 2001, v. 29, No. 6, p. 1053-1080.

BORJA DE MOZOTA, B. Design Management: Using Design to Build Brand Value and Corporate Innovation. New York: Allworth, 2003.

BRUCE, M.; Cooper, R.; Vazquez, D. Effective design management for small businesses. Design Studies, 1999, v. 20.

CAPALDO, A. Network Structure and Innovation: The Leveraging of a Dual Network as a Distinctive Relational Capability. Strategic Management Journal, 2007, v. 28, p. 585-608.

CHEN, S. Task partitioning in new product development teams: A knowledge and learning perspective. Journal of Engineering and Technology Management, 2005, v. 22, p. 291-314.

COX, J.; Spencer, M.S. Manual da teoria das restrições. Porto Alegre: Bookman, 2002.

DAVENPORT, T.H.; Prusak, L. Working Knowledge: How Organizations Manage What They Know. Boston: Harvard Business School Press, 1998.

DMI - Design Management Institute. Disponível em: 〈www.dmi.org〉. Acessado em: 21 de maio, 2016.

FLICK, U. Desenho da Pesquisa Qualitativa. Porto Alegre: Artmed, 2009.

LIBÂNIO, C.S. O papel do profissional de design e suas interfaces na gestão de design: um estudo de caso. Dissertação de Mestrado - PPGEP/UFRGS, 2011.

LIBÂNIO, C.S. Competências na formação e integração de indivíduos e equipes na gestão de design: um framework para a indústria do vestuário. Tese de Doutorado - PPGEP/UFRGS, 2014.

LOUFRANI-FEDIDA, S.; Angué, K. Pour une approche transversale et globale des compétences dans les organisations par projets. In: Retour D., Picq T., Defelix C. (eds). Gestion des compétences: nouvelles relations nouvelles dimensions. Paris: Vuibert, 2009, p. 123-148.

MALHOTRA, N. Pesquisa de marketing: uma orientação aplicada. 6oed. Porto Alegre: Bookman, 2012.

MARCONI, M.A.; Lakatos, E.M. Fundamentos da metodologia científica. São Paulo: Atlas, 2003.

MISHRA, A.A., Shah, R. In union lies strength: Collaborative competence in new product development and its performance effects. Journal of Operations Management, 2009, v. 27, p. 324338.

NOVAK, J.D.; Cañas, A.J. The Origins of the Concept Mapping Tool and the Continuing Evolution of the Tool. Information Visualization Journal, 2005, v.5, No. 3.

NOVAK, J.D.; Cañas, A.J. The Theory Underlying Concept Maps and How to Construct and Use Them. Technical Report IHMC CmapTools 2006-2008, Florida Institute for Human and Machine Cognition, 2008.

OLSON, E.M.; Cooper, R.; Slater, S.F. Design Strategy and Competitive Advantage. Business Horizons, 1998, march-april.

OSTERLUND, J.; Loven, E. Information versus Inertia: A Model for Product Change with Low Inertia. Systems Research and Behavioral Science, 2005, v. 22, p. 547-560.

RAVASI, D.; Lojacono, G. Managing Design and Designers for Strategic Renewal. Long Range Planning, 2005, v. 38, p. 51-77.

RETOUR, D. Progressos e limites da gestão por competências na França. In: Dutra, J.S.; Fleury, M.T.L.; Ruas, R. Competências: conceitos, métodos e experiências. São Paulo: Atlas, 2012. 